\title{
Management of C1-2 traumatic fractures using an intraoperative 3D imaging-based navigation system
}

\author{
Francesco Costa, MD, ${ }^{1}$ Alessandro Ortolina, MD, ${ }^{1}$ Luca Attuati, MD, ${ }^{1}$ Andrea Cardia, MD, ${ }^{1}$ \\ Massimo Tomei, MD, ${ }^{1}$ Marco Riva, MD, ${ }^{1}$ Luca Balzarini, MD, ${ }^{2}$ and Maurizio Fornari, MD ${ }^{1}$
}

Departments of ${ }^{1}$ Neurosurgery and ${ }^{2}$ Radiology, Humanitas Clinical and Research Center, Rozzano, Milan, Italy

OBJECT Fractures of $\mathrm{C}-1$ and $\mathrm{C}-2$ are complex and surgical management may be difficult and challenging due to the anatomical relationship between the vertebrae and neurovascular structures. The aim of this study was to evaluate the role, reliability, and accuracy of cervical fixation using the 0-arm intraoperative 3D image-based navigation system.

METHODS The authors evaluated patients who underwent a navigation system-based surgery for stabilization of a fracture of C-1 and/or C-2 from August 2011 to August 2013. All of the fixation screws were intraoperatively checked and their position was graded.

RESULTS The patient population comprised 17 patients whose median age was 47.6 years. The surgical procedures were as follows: anterior dens screw fixation in 2 cases, transarticular fixation of C-1 and C-2 in 1 case, fixation using the Harms technique in 12 cases, and occipitocervical fixation in 2 cases. A total of 67 screws were placed. The control intraoperative CT scan revealed 62 screws (92.6\%) correctly placed, 4 (5.9\%) with a minor cortical violation $(<2 \mathrm{~mm})$, and only 1 screw (1.5\%) that was judged to be incorrectly placed and that was immediately corrected. No vascular injury of the vertebral artery was observed either during exposition or during screw placement. No implant failure was observed.

CONCLUSIONS The use of a navigation system based on an intraoperative CT allows a real-time visualization of the vertebrae, reducing the risks of screw misplacement and consequent complications.

http://thejns.org/doi/abs/10.3171/2014.10.SPINE14122

KEY WORDS cervical fracture; spinal navigation; O-arm; radiation dose; screw misplacement

$\mathrm{F}$ IXATION of C1-2 is a challenging surgical procedure because of the anatomical characteristics of the two vertebrae. Since 1987 transarticular screw fixation, as described by Magerl and Seemann, ${ }^{19}$ has represented the gold-standard approach for posterior $\mathrm{C} 1-2$ fixation because of its biomechanical effects. However, many associated complications have been cited, including the risk of vertebral artery (VA) injury and neural injuries, and different techniques, producing comparable biomechanical stability, ${ }^{12,16}$ have been proposed. ${ }^{9-11}$ Despite the adoption of these techniques and variations thereof, screw insertion into cervical pedicles, lateral masses, laminae, or the dens remains challenging, especially in cases of traumatic fractures where the anatomy has been altered. Because of this, intraoperative technologies, such as image-guided systems (IGSs), have been increasingly used to help minimize risks. Spinal navigation based on CT scans is now recognized as a valuable tool for improving the accuracy and safety of screw placement. . $5,22,26^{5,26}$

Cervical spinal navigation based on preoperative 3DCT scans can effectively assist in reducing the risks of VA, spinal cord, and nerve root injuries, especially in the C1-2 region. ${ }^{8,25}$ However, while the patient is prone during surgery, the anatomical relationships may not match those depicted on preoperative CT scans obtained while the patient was supine. This discrepancy has led to navigation errors and prolonged surgical times, as well as to a serious unintended breach of the bony wall protecting neurovascular structures. Intraoperative 3D image-based navigation reduces this kind of complication, providing greater accuracy in instrument-assisted techniques. Moreover, the acquisition of intraoperative images in patients with spinal trauma offers a more clearly defined view of the operative anatomy and subsequently a better defined surgical strategy. ${ }^{14,23}$ To 
date, there have been few reports in the literature regarding the application of spinal navigation using the O-arm Surgical Imaging System (Medtronic Inc.) in cervical trauma; a total of 28 patients have been reported on ( 6 by Ishikawa et al., ${ }^{13} 14$ by Schouten et al., ${ }^{23}$ and 8 by Ailawadhi ${ }^{1}$ ).

The aim of our study was to analyze the reliability of an IGS based on intraoperative CT scanning (O-Arm system) in the management of traumatic fractures of C-1 and C-2, with surgery conducted via both anterior and posterior approaches in a consecutive series of a single institution.

\section{Methods}

This series included all patients who presented to our neurosurgical department between August 2011 to August 2013 with a diagnosis of C-1 and/or C-2 traumatic fractures requiring fixation surgery. Fractures were diagnosed using reconstructed CT scans.

Options for instrumentation construct included the following: transarticular C1-2 fixation (the Magerl technique), C-1 lateral mass to C-2 isthmic-pedicle screw fixation (the Harms technique), occipitocervical fixation, and anterior lag-screw fixation.

In particular, the surgical approach was chosen following consideration of different factors, such as the type and characteristics of the fracture pattern. The Harms technique was chosen mainly because its biomechanical characteristics are similar to those of other fixation techniques and it permits an easier approach. For the same reason, the Magerl technique was no longer used after the first case because of its greater complexity. A Type II odontoid fracture without dislocation was preferably treated using an anterior lag-screw fixation, while occipitocervical fixation was used as salvage technique in those cases in which the other approach was not considered safe and/or possible or in cases of low-quality bone, as in elderly patients.

All surgical procedures (both anterior and posterior approaches) were performed using a navigation system (StealthStation S7, Medtronic Inc.) based on an intraoperative $\mathrm{CT}$ scan acquired with the $\mathrm{O}$-arm system. The scanning time with the $\mathrm{O}$-arm system was about 13 seconds (normal definition) with the following cervical protocol: $120 \mathrm{kVp}$ (kilovoltage peak), varying milliamperes, 1 rotation, 391 pulses of $10 \mathrm{msec}$ each (beam-on time $3.91 \mathrm{sec} /$ acquisition). The doses received by the surgeon were measured using an electronic dose meter attached at breast level. Radiation dosage for the patient in the operating room was defined using the technical parameters and dose report data (scan area, scan length, slice thickness, $\mathrm{kVp}$, mAs [milliamperes per second], pitch and dose-length product) abstracted directly by the $\mathrm{O}$-arm system.

For posterior approaches the navigation reference frame was fixed to the spinous process of $\mathrm{C}-3$ or $\mathrm{C}-4$, and for anterior approaches the passive frame was fixed directly to the radiolucent table.

\section{Proper Length and Diameter of the Screws Decided Intraoperatively According to CT Images of the Navigation System}

After positioning the screws, a second intraoperative CT scan was obtained with the O-arm system to check and classify the correct positioning of the screws. During surgery, the operating surgeon directly assessed the screws to determine any misplacement needing to be corrected. The evaluation and classification of screw positions were performed by an independent radiologist (L.B.), who was not aware of the particular screw insertion technique. The screw position was graded as follows: 1) screw inside the bone (lateral mass, pedicle, and/or isthmic) or 2) perforation of the cortex by up to $2 \mathrm{~mm}$, from 2 to $4 \mathrm{~mm}$, or by more than $4 \mathrm{~mm} .{ }^{21}$ The perforation location was analyzed in axial, coronal, and sagittal planes and therefore classified as lateral, inferior, medial, or superior according to the classification described by Laine et al. ${ }^{17}$

Clinical and radiological follow-up studies were assessed retrospectively. Fusion status was assessed using standard radiographs (anteroposterior and lateral), and CT scans were reserved for inspection in cases of any sign of implant failure; clinical follow-up was assessed using the neurological exam; and functional recovery was determined according to Denis' functional pain and work scale. ${ }^{6}$

\section{Results}

From August 2011 to August 2013, 23 patients sustained traumatic fractures of $\mathrm{C}-1$ and/or C-2. Of this population 6 patients were treated conservatively (halo jacket or cervical orthosis) because of their age and comorbidities, which did not allow them to undergo a surgical procedure, and 17 patients (73.9\%) underwent cervical fixation; these 17 patients form the basis of the present study.

The population comprised 9 males (52.9\%) and 8 females (47.1\%), whose median age was 47.6 years (range 22-78 years). Fracture locations were as follows: $\mathrm{C}-1$ in 4 cases (23.5\%); C-2 in 10 cases (58.9\%); and both $\mathrm{C}-1$ and $\mathrm{C}-2$ in 3 cases $(17.6 \%)$.

Surgical procedures included the following 15 posterior approaches $(88.2 \%)$ and 2 anterior approaches (11.8\%): transarticular C1-2 fixation (Magerl technique) in 1 case (5.9\%); C-1 lateral mass to C-2 isthmic pedicle screw (Harms technique) in 12 cases (70.5\%); occipitocervical fixation in 2 cases (11.8\%); and anterior lag-screw fixation in 2 cases (11.8\%) (Fig. 1).

For the posterior approaches a cross-link was used in 4 cases $(26.6 \%)$, whereas a wire-augmented fusion with iliac crest bone (according to the technique described by Dickman et al. ${ }^{7}$ ) was used in 5 cases (33.3\%).

The mean operative time was 161.7 minutes (range 65254 minutes). A total of 67 screws (range 1-7) were placed using a navigation system based on intraoperative CT scans acquired with the O-arm system: 24 screws (35.8\%) in C-1; 30 (44.8\%) in C-2; and 13 (19.4\%) in the subaxial lateral masses. A summary of results is presented in Table 1.

According to the Neo et al. and Laine et al. classifications, a total of 62 screws (92.6\%) were classified as correctly placed (Grade 0), 4 (5.9\%) graded as I, and only 1 $(1.5 \%)$ with a violation graded as II in the cranio-caudal direction; this screw was changed and the reposition was graded as 0 . No major cortical violation was observed. Table 2 summarizes the results of screw placement in relationship to the fixation level. 


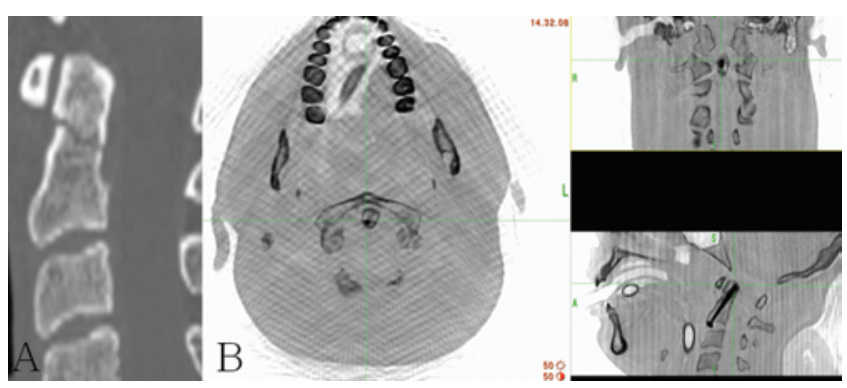

FIG. 1. Dens fracture. A: Preoperative CT scan with sagittal reconstruction. B: Intraoperative CT scans acquired with 0 -arm system showing the correct position of the lag screw in axial, sagittal, and coronal planes. Figure is available in color online only.

Information regarding the anatomy of $\mathrm{C}-1$ and $\mathrm{C}-2$, obtained with the $\mathrm{O}$-arm system, allowed the fixation strategy for 5 screws $(7.5 \%)$ to be changed intraoperatively. In particular, the entry point and the trajectory of the screws were changed in 3 cases because the bony anatomy was distorted due to the characteristic of the fracture itself. It was not possible to position an isthmic screw in C-2 in 1 case due to the presence of an anatomical variant of the VA, passing through all of the isthmus. In the fifth case, the trajectory of a screw was changed in C-1 due to a massive venous bleed of the plexus, and the screw was therefore placed in the translaminar lateral mass of C-1.

No intraoperative complication such as injury of the VA, spinal nerve root, or spinal cord was recorded in this series. Two patients received a blood transfusion during surgery to manage venous bleeding of the $\mathrm{C}-1$ plexus. The postoperative course was uneventful in all patients except in one patient who developed a superficial wound infec- tion 10 days after surgery, which was treated with surgical debridement and antibiotic therapy.

A total of $38 \mathrm{CT}$ scans were obtained (mean 2.2); in 3 cases a control CT scan was acquired before surgery to verify the correct alignment of the fracture reduction, and in 1 case CT scans were obtained to verify the accuracy of a repositioned screw.

The intraoperative radiation exposure, in following our cervical protocol, was as follows: $120 \mathrm{kVp}, 25 \mathrm{~mA}, 97.75$ $\mathrm{mAs}$, and 12.41 CT dose index, while the dose-length product ranged from 85.4 to 198.55 , according to the collimation used, which corresponded to a mean of $0.78 \mathrm{mSv}$ (range $0.5-1.1 \mathrm{mSv}$ ) for each patient for each CT acquisition. The mean surgical radiation dose received by the patient was $1.83 \mathrm{mSv}$, while the dose per surgery received by the surgeon performing the imaging acquisition (protected behind a lead wall) at breast level was $0.01 \mathrm{mSv}$. The dose outside the operating room (where the other members of the team were at the moment of the image acquisition) was $0 \mathrm{mSv}$.

During the follow-up period (mean 15.2 months, range 5-29 months) 16 patients (94.1\%) exhibited a favorable clinical recovery (defined as a Denis grade of P1 or P2 [no pain or occasional mild pain not requiring medication, respectively]), and only 1 patient required occasional medication for moderate pain (Denis grade of P3) at last follow-up; Denis' functional work scale showed a return to previous work or activity (Grade W1) in 14 cases (82.4\%) and a return to work with some restraints (Grade W2) in 2 cases (11.8\%); a major limitation (Grade W3) was only present in 1 case. Satisfactory radiological fusion signs were assessed in 15 patients (88.2\%). One patient had signs of bony resorption around the screws placed in $\mathrm{C}-2$

TABLE 1. General information of fracture and surgical procedure of population

\begin{tabular}{|c|c|c|c|c|c|c|c|c|c|}
\hline \multirow[b]{2}{*}{$\begin{array}{l}\text { Patient } \\
\text { No. }\end{array}$} & \multirow[b]{2}{*}{ Type of Trauma } & \multirow[b]{2}{*}{$\begin{array}{l}\text { Site of } \\
\text { Fracture }\end{array}$} & \multirow[b]{2}{*}{$\begin{array}{l}\text { Type of } \\
\text { Fracture* }^{*}\end{array}$} & \multirow[b]{2}{*}{ Type of Surgery } & \multirow[b]{2}{*}{$\begin{array}{c}\text { Mean Op } \\
\text { Time (mins) }\end{array}$} & \multirow[b]{2}{*}{$\begin{array}{l}\text { No. of } \\
\text { Screws }\end{array}$} & \multirow[b]{2}{*}{$\begin{array}{l}\text { No. CT } \\
\text { Scans }\end{array}$} & \multicolumn{2}{|c|}{ No. of Cases } \\
\hline & & & & & & & & $\begin{array}{c}\text { Screw } \\
\text { Perforation }\end{array}$ & $\begin{array}{c}\text { Screw } \\
\text { Replacement }\end{array}$ \\
\hline 1 & Precipitation & $\mathrm{C}-1$ & D & Harms fixation & 113 & 4 & 2 & 0 & 0 \\
\hline 2 & Accidental fall & $\mathrm{C}-2$ & III & Harms fixation & 224 & 4 & 2 & 1 & 0 \\
\hline 3 & Plunge & $\mathrm{C}-1$ & $E$ & Harms fixation & 236 & 4 & 2 & 0 & 0 \\
\hline 4 & Traffic accident & $\mathrm{C}-2$ & III & Harms fixation & 254 & 6 & 3 & 1 & 1 \\
\hline 5 & Beating & $\mathrm{C}-1$ & $D$ & Harms fixation & 200 & 4 & 2 & 1 & 0 \\
\hline 6 & Traffic accident & $\mathrm{C}-2$ & II & Anterior lag-screw fixation & 105 & 1 & 2 & 0 & 0 \\
\hline 7 & Traffic accident & $\mathrm{C}-1$ \& C-2 & $B+I I$ & Occipitocervical fixation & 165 & 7 & 2 & 0 & 0 \\
\hline 8 & Plunge & $\mathrm{C}-2$ & II & Magerl fixation & 195 & 2 & 3 & 0 & 0 \\
\hline 9 & Precipitation & C-1 & $E$ & Harms fixation & 82 & 4 & 2 & 0 & 0 \\
\hline 10 & Traffic accident & $\mathrm{C}-1$ \& C-2 & $D+I I I$ & Harms fixation & 128 & 4 & 2 & 0 & 0 \\
\hline 11 & Accidental fall & $\mathrm{C}-2$ & III & Harms fixation & 65 & 4 & 2 & 0 & 0 \\
\hline 12 & Accidental fall & $\mathrm{C}-2$ & II & Harms fixation & 110 & 4 & 2 & 0 & 0 \\
\hline 13 & Traffic accident & $\mathrm{C}-2$ & II & Harms fixation & 185 & 4 & 3 & 1 & 0 \\
\hline 14 & Precipitation & $\mathrm{C}-2$ & III & Anterior lag-screw fixation & 105 & 1 & 2 & 0 & 0 \\
\hline 15 & Traffic accident & $C-1 \& C-2$ & $D+I I I$ & Occipitocervical fixation & 205 & 6 & 2 & 0 & 0 \\
\hline 16 & Traffic accident & $\mathrm{C}-2$ & III & Harms fixation & 240 & 4 & 3 & 1 & 0 \\
\hline 17 & Traffic accident & $\mathrm{C}-2$ & II & Harms fixation & 136 & 4 & 2 & 0 & 0 \\
\hline
\end{tabular}

${ }^{*}$ Fracture type was classified according to Levine and Edwards ${ }^{18}$ for $\mathrm{C}-1$ fractures and to Anderson and D'Alonzo ${ }^{2}$ for $\mathrm{C}-2$ fractures. 
TABLE 2. Classification of screw position*

\begin{tabular}{lcccc}
\hline \multirow{2}{*}{ Factor } & \multicolumn{4}{c}{ No. of Screws (\%) } \\
\cline { 2 - 5 } & C-1 Lateral Mass & C-2 Isthmic & Other & Total \\
\hline Correct position (Grade 0) & $21(31.3)$ & $28(41.8)$ & $13(19.4)$ & $62(92.5)$ \\
\hline Violation & & & & $4(6.0)$ \\
\hline$<2 \mathrm{~mm}$ (Grade I) & $1(1.5): \mathrm{S}$ & $3(4.5): 2 \mathrm{M}, 1 \mathrm{~S}$ & 0 & $1(1.5)$ \\
\hline$>2$ to $\leq 4 \mathrm{~mm}$ (Grade II) & 0 & $1(1.5): \mathrm{S}$ & 0 & 67 \\
\hline$>4 \mathrm{~mm}$ (Grade III) & 0 & 0 & 0 & 13 \\
\hline Total & 22 & 32 & &
\end{tabular}

documented on control radiographs and confirmed on CT performed at the 5 month-follow-up; the study, however, showed initial signs of fusion between C-1 and C-2 due to the iliac crest graft. Clinically, the patient did not complain of any pain or limitation; in this case the treatment was conservative (use of cervical brace). In a second case, a 78-year-old patient, who had undergone occipitocervical fixation to treat a dens fracture, CSF leakage resulting from mobilization of an occipital screw 4 months after surgery led to a right subdural hematoma. The patient underwent a second surgery to remove the implant (a control CT scan showed that fusion had been achieved); the CSF fistula resolved and the subdural hematoma was drained. At the last follow-up 9 months after the first surgery, the patient has cervical rigidity, without pain, but some limitation in normal activities of daily living (Grade W3 on the Denis work scale). No neurological deficit was present.

\section{Discussion}

Cervical screw fixation (anterior and posterior) provides immediate and significantly greater stabilization for C1-2 fractures than conservative treatment. Moreover, the surgical management of these fractures can effectively assist in faster recovery, reducing the risks of systemic comorbidities (such as pneumonia, deep venous thrombosis, loss of muscle tone and strength, reduced personal autonomy) and pseudarthrosis, especially in elderly people.

However, the surgical approaches to $\mathrm{C} 1-2$ fractures are challenging both because of the anatomy of the vertebrae and the distortion of the normal anatomy by the fracture and consequent instability.

Thus, image guidance plays an important role in the management of fractures in this region. In particular, these systems offer a lot of information regarding the anatomy of $\mathrm{C}-1$ and $\mathrm{C}-2$, in our experience allowing a change in fixation strategy during surgery. In particular, the entry point and the trajectory of the screws can be assessed and eventually changed according to the distortion of the bony anatomy due to the characteristics of the fracture itself. In our population, for example, it was not possible to position an isthmic screw in $\mathrm{C}-2$ in one case due to the presence of an anatomic variant of the VA passing through all the isthmus, while in another case the trajectory of a screw was changed in C-1 because of a massive venous bleed of the plexus; in this case the screw was placed in the mass of C-1 via a translaminar access.
However, the use of technology, and in particular of neuronavigation, is advocated mainly to reduce the risk of screw misplacement. Although cortical perforation by a screw does not necessarily cause clinical complications, bony wall perforation can increase the risk of neurovascular injury, such as spinal cord, nerve root, or VA injury, as well as profuse venous bleeding. In fact, using a conventional technique, Kotani et al. ${ }^{15}$ reported a perforation rate of $6.7 \%$ (45 of 664 screws) and 2 of 45 screws that caused radiculopathy. The rate of cortical violation decreases when an IGS is used, ${ }^{1,4,13-15,23,25}$ with a total rate ranging from $2 \%$ to $2.8 \%$ (graded as cortex violation $>2 \mathrm{~mm}$ ). Our experience using the $\mathrm{O}$-arm system is in line with these results, with a significant cortical violation (Grade II) observed with 1 screw (1.5\%), which was changed intraoperatively. Before the introduction of this device we managed this type of fracture using an IGS based on a preoperative CT scan, with a similar rate of cortical violation (1.8\%). However, it is difficult to correlate these results directly, due to various possible biases. For example, before the introduction of the $\mathrm{O}$-arm system, the surgical treatment of choice for a $\mathrm{C} 1-2$ fracture in our institute was occipitocervical fixation with lateral mass screws between $\mathrm{C}-2$ and $\mathrm{C}-5$, which is a less challenging technique than the Harms technique, for example, which is actually the most common technique for us $(70.5 \%)$.

Furthermore, it is clearly impossible to eliminate the risk of cortical violation completely when using a navigation system. Different parameters and variability must be considered in the treatment of traumatic fractures, especially those of the $\mathrm{C} 1-2$ region, which can lead to some degree of screw malpositioning.

When using navigation of the cervical spine based on preoperative 3D-CT data, the main drawback lies in the different anatomical relationships that may exist between the time of CT scan acquisition and the surgical procedure, particularly with regard to posterior approaches (supine vs prone positioning). This discrepancy in the anatomy may lead to navigation errors and thus prolonged surgical time. Intraoperative 3D image-based navigation reduces, but does not avoid, this kind of complication completely. One of the most common causes of inaccuracy is dictated by the positioning of the frame of the navigation system. When fixed to a spinous process (we usually avoid the C-2 spinous process), it is possible that the frame will move. ${ }^{14}$ Fixation of the reference frame directly to the Mayfield clamp, as adopted by other authors, may avoid its mobiliza- 
tion, but this can lead to difficulties in visualization of the frame by the navigation system camera due to the presence of the surgeon. Another common cause of inaccuracy in cases involving a traumatic fracture is the mobility of bone fragments, which leads to C-1 and C-2 instability that can cause variations of the anatomy with respect to the 3D images reconstructed by the navigation system.

In our cases we observed a minor cortical violation for 4 screws (5.9\%), which we judged to be acceptable, because the violation did not affect neurovascular structures. Only 1 screw (1.5\%) caused cortical violation of more than $2 \mathrm{~mm}$ (Grade II) in the craniocaudal direction; this error was due to the mobilization of the passive frame during surgery.

However, even though an error may occur with these navigation devices (such as Iso-C3D and O-arm systems), it is possible to perform intraoperative $3 \mathrm{D}$ imaging so as to gain immediate control and make any correction of a misplaced screw that is necessary, ${ }^{23}$ thus avoiding the need for revision surgery. In our series, for example, the positioning of one misplaced screw was corrected intraoperatively, and the final position of the screw was shown to be correct on a third CT scan. This capability is, in our opinion, the truly great advantage of this tool. In fact, the ability to acquire control CT scans in the operating room not only allows for assessment of screw accuracy but can also be useful after patient positioning in judging the alignment of the reduction of the fracture. In our series, the position of the patient (usually determined using standard fluoroscopy) was also assessed using control CT scans in 3 cases in which fluoroscopy failed to clearly show the fracture reduction. The position of the patient was corrected in two cases according to information from a preoperative CT scan.

While the application of the O-arm system for the posterior approach in the cervical spine has also been described in cases of traumatic fracture, ${ }^{1}$ its use in cases requiring anterior fixation has still not been described. However, good results have been reported in association with anterior lag-screw fixation combined with Iso-C3D guidance. . $^{14,20,27}$ Our experience with lag-screw fixation (involving only 2 cases) appears to be in line with that reported in other series, with similar mean surgical times reported in the literature ranging from 83 to 108 minutes compared with 85 to 100 minutes in our series. From a radiological perspective, the results were satisfactory and uneventful in both cases.

Although the results of the O-arm system in the surgical management of C1-2 fractures are good, it should be noted that there are some drawbacks to its use, especially in the initial cases. One of the most critical points affecting the learning curve is represented, in our experience, by the positioning of the patient. The Mayfield clamp with its system being fastened to the bed presents a relevant encumbrance that may be in conflict with the O-arm itself, especially in the inferior part, when the surgeon tries to center the upper cervical spine in the gantry (Fig. 2). To avoid this conflict, with the chance of damaging the $\mathrm{O}$-arm, it is important to keep the O-arm as low to the ground as possible. The use of a standard operating room table adaptor (not radiolucent, as in our cases) for the Mayfield or DORO clamp does not affect the quality of the imaging in the $\mathrm{C} 1-2$ region, while in the lower cervical and

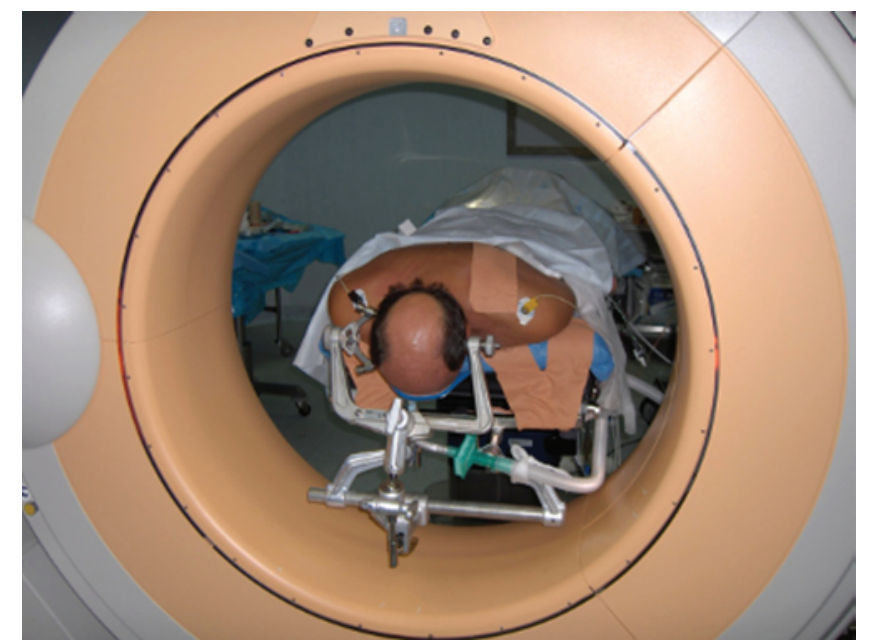

FIG. 2. Positioning of patient and relationship between $\mathrm{O}$-arm and Mayfield clamp. Figure is available in color online only.

upper thoracic spine (from C-6 to T-2 approximately), the artifacts are more relevant and may alter the navigation system. However, use of carbon fiber rails and radiolucent skull clamps will solve this problem.

As the quality of the images created by the O-arm system is fairly good, and as the navigation system allows for a precise recognition of the bony structures, it should be noted that the resolution is not of the same quality as it is with diagnostic CT scanning. This is particularly relevant for the control scan on which the presence of metallic scatter from the instrumentation could make the definition of accuracy difficult, especially in Grade 0 or I cases $(<2$ $\mathrm{mm})$. Thus, our results may underestimate the definition of screw violation of Grade I; however, as stated before, a violation of less than $2 \mathrm{~mm}$ is considered acceptable and uneventful, as documented by the clinical follow-up.

Finally, another concern involves radiation doses delivered by the O-arm system: Our results showed that with the cervical protocol the mean surgical radiation dose was $1.83 \mathrm{mSv}$, which obviously must be added to the dose produced by the diagnostic preoperative CT scan (around 3.6 $\mathrm{mSv}){ }^{24}$ The adjunctive dose from the intraoperative CT scan for the patient may cause some concern, but on the other hand it can be regarded as acceptable considering the effectiveness of this technique. Because the positioning of the screw can be checked intraoperatively, leading to any immediate correction, reoperation for misplaced screws can be avoided, which is a great advantage in many respects (such as clinical and medicolegal issues). However, the impact of the radiation dose for the patient may trigger questions and considerations from an ethical point of view. It is quite difficult to define the limit between the effectiveness of this technology and the stochastic risks to the head and neck related to the radiation dose.

Furthermore, the radiation doses the surgeons and other members of the team are exposed to is negligible, from 0 to $0.01 \mathrm{mSv}$.

\section{Conclusions}

In summary, spinal navigation in the management of 
C1-2 fractures is a feasible and safe technique when performed using the $\mathrm{O}$-arm system. It can be used in conjunction with the preferred surgical techniques (anterior, posterior, Magerl, Harms fixation, etc.). Furthermore, it is also helpful if, for anatomical or other reasons (such as profuse venous bleeding during positioning C-1 screw), standard procedures need to be modified. However, even if great effort is made to achieve good results with the Oarm system, we want to stress that this technology cannot completely eliminate all risks associated with spinal instrumentation, and the experience and skill of the surgeons remain essential determining factors.

\section{References}

1. Ailawadhi P, Agrawal D, Satyarthee GD, Gupta D, Sinha S, Mahapatra AK: Use of O-arm for spinal surgery in academic institution in India: experience from JPN apex trauma centre. Neurol India 59:590-593, 2011

2. Anderson LD, D'Alonzo RT: Fractures of the odontoid process of the axis. J Bone Joint Surg Am 56:1663-1674, 1974

3. Amiot LP, Labelle H, DeGuise JA, Sati M, Brodeur P, Rivard $\mathrm{CH}$ : Computer-assisted pedicle screw fixation. A feasibility study. Spine (Phila Pa 1976) 20:1208-1212, 1995

4. Bolger C, Wigfield C: Image-guided surgery: applications to the cervical and thoracic spine and a review of the first 120 procedures. J Neurosurg 92 (2 Suppl): 175-180, 2000

5. Costa F, Cardia A, Ortolina A, Fabio G, Zerbi A, Fornari M: Spinal navigation: standard preoperative versus intraoperative computed tomography data set acquisition for computerguidance system: radiological and clinical study in 100 consecutive patients. Spine (Phila Pa 1976) 36:2094-2098, 2011

6. Denis F: Spinal instability as defined by the three-column spine concept in acute spinal trauma. Clin Orthop Relat Res (189): 65-76, 1984

7. Dickman CA, Sonntag VKH, Papadopoulos SM, Hadley MN: The interspinous method of posterior atlantoaxial arthrodesis. J Neurosurg 74:190-198, 1991

8. Finn MA, Apfelbaum RI: Atlantoaxial transarticular screw fixation: update on technique and outcomes in 269 patients. Neurosurgery 66 (3 Suppl):184-192, 2010

9. Goel A, Desai KI, Muzumdar DP: Atlantoaxial fixation using plate and screw method: a report of 160 treated patients. Neurosurgery 51:1351-1357, 2002

10. Goel A, Laheri V: Plate and screw fixation for atlanto-axial subluxation. Acta Neurochir (Wien) 129:47-53, 1994

11. Harms J, Melcher RP: Posterior C1-C-1 fusion with polyaxial screw and rod fixation. Spine (Phila Pa 1976) 26:2467-2471, 2001

12. Hott JS, Lynch JJ, Chamberlain RH, Sonntag VKH, Crawford NR: Biomechanical comparison of C1-2 posterior fixation techniques. J Neurosurg Spine 2:175-181, 2005

13. Ishikawa Y, Kanemura T, Yoshida G, Matsumoto A, Ito Z, Tauchi R, et al: Intraoperative, full-rotation, three-dimensional image $(\mathrm{O}$-arm) -based navigation system for cervical pedicle screw insertion. Clinical article. J Neurosurg Spine 15:472-478, 2011

14. Kantelhardt SR, Keric N, Giese A: Management of C2 fractures using Iso-C(3D) guidance: a single institution's experience. Acta Neurochir (Wien) 154:1781-1787, 2012

15. Kotani Y, Abumi K, Ito M, Minami A: Improved accuracy of computer-assisted cervical pedicle screw insertion. J Neurosurg 99 (3 Suppl):257-263, 2003

16. Kuroki H, Rengachary SS, Goel VK, Holekamp SA, Pitkänen
V, Ebraheim NA: Biomechanical comparison of two stabilization techniques of the atlantoaxial joints: transarticular screw fixation versus screw and rod fixation. Neurosurgery 56 (1 Suppl):151-159, 2005

17. Laine T, Mäkitalo K, Schlenzka D, Tallroth K, Poussa M, Alho A: Accuracy of pedicle screw insertion: a prospective CT study in 30 low back patients. Eur Spine J 6:402-405, 1997

18. Levine AM, Edwards CC: The management of traumatic spondylolisthesis of the axis. J Bone Joint Surg Am 67:217226, 1985

19. Magerl F, Seemann PS: Stable posterior fusion of the atlas and axis by transarticular screw fixation, in Kehr P, Weidner A (eds): Cervical Spine. Vienna: Springer-Verlag, 1987, pp 322-327

20. Martirosyan NL, Kalb S, Cavalcanti DD, Lochhead RA, Uschold TD, Loh A, et al: Comparative analysis of isocentric 3-dimensional C-arm fluoroscopy and biplanar fluoroscopy for anterior screw fixation in odontoid fractures. J Spinal Disord Tech 26:189-193, 2013

21. Neo M, Sakamoto T, Fujibayashi S, Nakamura T: The clinical risk of vertebral artery injury from cervical pedicle screws inserted in degenerative vertebrae. Spine (Phila Pa 1976) 30:2800-2805, 2005

22. Nolte LP, Zamorano LJ, Jiang Z, Wang Q, Langlotz F, Berlemann U: Image-guided insertion of transpedicular screws. A laboratory set-up. Spine (Phila Pa 1976) 20:497-500, 1995

23. Schouten R, Lee R, Boyd M, Paquette S, Dvorak M, Kwon $\mathrm{BK}$, et al: Intra-operative cone-beam CT (O-arm) and stereotactic navigation in acute spinal trauma surgery. J Clin Neurosci 19:1137-1143, 2012

24. Smith-Bindman R, Lipson J, Marcus R, Kim KP, Mahesh M, Gould R, et al: Radiation dose associated with common computed tomography examinations and the associated lifetime attributable risk of cancer. Arch Intern Med 169:20782086, 2009

25. Uehara M, Takahashi J, Hirabayashi H, Hashidate H, Ogihara N, Mukaiyama K, et al: Computer-assisted C1-C2 transarticular screw fixation "Magerl Technique" for atlantoaxial instability. Asian Spine J 6:168-177, 2012

26. Van de Kelft E, Costa F, Van der Planken D, Schils F: A prospective multicenter registry on the accuracy of pedicle screw placement in the thoracic, lumbar, and sacral levels with the use of the O-arm imaging system and StealthStation Navigation. Spine (Phila Pa 1976) 37:E1580-E1587, 2012

27. Yang YL, Fu BS, Li RW, Smith PN, Mu WD, Li LX, et al: Anterior single screw fixation of odontoid fracture with intraoperative Iso-C 3-dimensional imaging. Eur Spine J 20:1899-1907, 2011

\section{Author Contributions}

Conception and design: Costa. Acquisition of data: Attuati, Tomei, Riva. Analysis and interpretation of data: Costa, Ortolina, Cardia, Balzarini. Drafting the article: Costa. Critically revising the article: Costa, Ortolina, Cardia, Balzarini. Reviewed submitted version of manuscript: Costa, Balzarini, Fornari. Approved the final version of the manuscript on behalf of all authors: Costa. Administrative/technical/material support: Attuati, Tomei. Study supervision: Costa, Fornari.

\section{Correspondence}

Costa Francesco, Department of Neurosurgery, Humanitas Clinical and Research Center, Via A. Manzoni, 5620089 Rozzano, Milan, Italy. email: f.costa@outlook.it. 